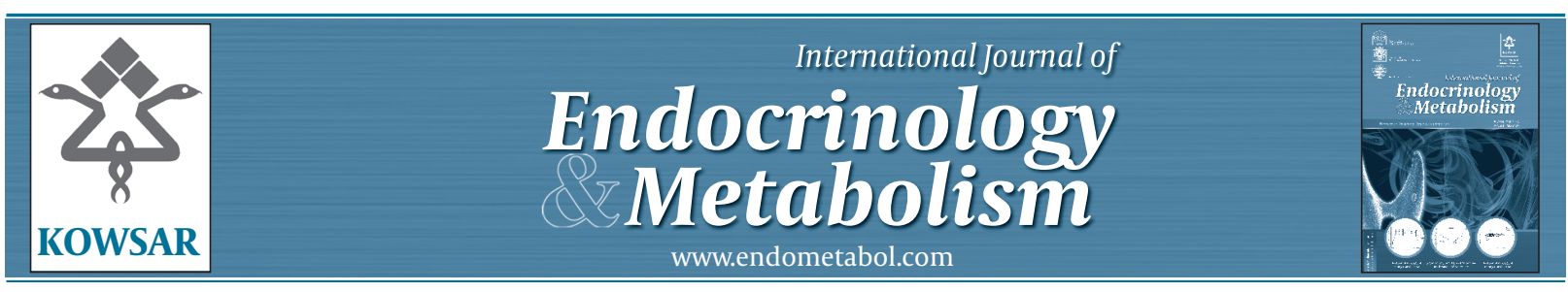

\title{
Which One Is More Important, Obesity or Cardio Metabolic Risk Factors?
}

\author{
Farhad Hosseinpanah ${ }^{1^{*}}$ \\ ${ }^{1}$ Obesity Research Center, Research Institute for Endocrine Sciences, Shahid Beheshti University of Medical Sciences, Tehran, IR Iran \\ * Corresponding author: Farhad Hosseinpanah, Obesity Research Center, Research Institute for Endocrine Sciences, Shahid Beheshti University of Medical \\ Sciences, P.O.Box: 19395-4763, Tehran, IR Iran.Tel.: +98-2122409309, Fax: +98-2122402463, E-mail: fhospanah@endocrine.ac.ir
}

Keywords: Obesity; Cardio Metabolic

Obesity defined as a BMI of 30 or above is a major health hazard, which is obviously linked to dyslipidemia, hypertension and type2 diabetes. However, clustering of CVD risk factors is different across the continuum of body mass index (BMI) leading to recognition of phenotype subgroups of obesity. Accordingly since the 1980s two well-known phenotypes of obesity have been described in medical literature i.e. "Metabolically obese but normal weight" (MONW) and "metabolically healthy but obese" (MHO) (1). Among American adults in the National Health and Nutrition Examination Survey (NHANES; 1999 to 2004), $23.5 \%$ of normal-weight adults were metabolically abnormal, whereas $51.3 \%$ of overweight adults and $31.7 \%$ of obese adults were metabolically healthy (2). Moreover few studies reported an increasing trend of MNOW. For instance a dramatic 4-fold increase in prevalence of metabolic syndrome has been reported among normal weight Tehranian adults during 6.6 years of follow up (3).There are controversial findings regarding the independent role of obesity in the development of CVD and all-cause mortality. Some studies have shown that obesity, regardless of the presence or absence of Metabolic syndrome and IR, was associated with a higher risk for Cardio metabolic comor- bidities (4). While, others have demonstrated that BMI, and other anthropometric indices, whether assessed singly or in combination, do not importantly improve cardiovascular disease risk prediction when additional information is available for systolic blood pressure, history of diabetes, and lipids (5). Accordingly, considering the different outcomes for the phenotypes, importance of metabolic abnormalities for predicting CVD events in comparison with weight status per se emerges as an important question. In fact it seems that some kinds of interaction exist between obesity and metabolic risk factors in the development of CVD outcomes. Obesity-related phenotypic characteristics and CVD outcomes have been investigated in several epidemiological studies yielding some conflicting results (6-12). The majority of studies have reported an increased risk of CVD in MNOW compared to MHO. Within the framework of Tehran Glucose and Lipid Study (TLGS), during a mean of 8.1 years of follow up, among 6,215 subjects aged $>30$ years free of CVD at baseline, we showed that, compared to normal weight subjects without dysmetabolic aspects, multivariate-adjusted hazard ratios for CVD events were 2.10 (95\% CI 1.36 to 3.26 ) and 1.07 (95\% CI 0.59 to 1.96 ) in normal weight subjects with dysmetabolic aspects and obese subjects

Article type: Editorial; Received: 28 Aug 2012, Revised: 01 Sep 2012, Accepted: 09 Sep 2012; DOI: 10.5812/ijem.7963

-Implication for health policy/practice/research/medical education:

This editorial covers a hot topic in fields of obesity and cardiovascular disease and can help reaserchers to design relevant studies and also healch care provider to pay more attention to metabolic risk factors.

Please cite this paper as:

Hosseinpanah F. Which One Is More Important, Obesity or Cardio Metabolic Risk Factors? Int J Endocrinol Metab. 2013;11(1):1-2. DOI: 10.5812/ijem.7963

Copyright (c) 2013,Research Institute For Endocrine Sciences and Iran Endocrine Society; Published by Kowsar Corp.

This is an Open Access article distributed under the terms of the Creative Commons Attribution License (http://creativecommons.org/licenses/by/3.0), which permits unrestricted use, distribution, and reproduction in any medium, provided the original work is properly cited. 
without dysmetabolic aspects respectively (9). A recent large and well conducted study by Hamer and Stamatakis also reported that metabolically healthy obese participants were not at increased risk of CVD and all-cause mortality following an average 7 years of follow up. Moreover metabolically unhealthy obese participants were at elevated risk of all-cause mortality compared with their metabolically healthy obese counterparts (HR 1.72,95\% CI 1.23-2.41) (10). However, other reports provided contradictory results regarding the benign nature of $\mathrm{MHO}(11,12)$. Johan Arnlov et al. investigated associations between cardiovascular disease and death in middle-aged men during more than 30 years of follow-up and found that men with metabolic syndrome had an increased risk of cardiovascular events, regardless of BMI status. However overweight and obese participants without metabolic syndrome or without IR also had an increased risk of cardiovascular events and total death compared with normal-weight men without metabolic syndrome or insulin resistance (12). These studies differed from each other in terms of varying definitions for the phenotypes, the types of outcomes and ascertainment methods used and length of follow up. The positive association between MHO and CVD outcomes observed with long term follows up, can be explained by possible metabolic deterioration of obese subjects who are free of metabolic abnormalities at baseline. However the natural course of metabolic syndrome incidence in healthy obese phenotype has not been investigated in long term prospective studies $(13,14)$. Taken together, there is no doubt regarding the increased risk of CVD in MNOW but further studies are needed to answer the question whether MHO is associated with CVD or not. This unanswered question has led to different recommendations by national and international guidelines in terms of the value of anthropometric indices for prediction of CVD outcomes (15-18). Moreover, a better understanding of MHO prognosis can help the physicians to identify those overweight or obese subjects who should be candidates for early intervention. Until we have definitive answers, it seems reasonable to put more weight on metabolic risk factors as compared to anthropometric measures especially BMI.

\section{Acknowledgements}

None declared.

\section{Financial Disclosure}

None declared.

\section{References}

1. Karelis AD, St-Pierre DH, Conus F, Rabasa-Lhoret R, Poehlman ET. Metabolic and body composition factors in subgroups of obesi- ty: what do we know? J Clin Endocrinol Metab. 2004;89(6):2569-75

2. Wildman RP, Muntner P, Reynolds K, McGinn AP, Rajpathak S Wylie-Rosett J, et al. The obese without cardiometabolic risk factor clustering and the normal weight with cardiometabolic risk factor clustering: prevalence and correlates of 2 phenotypes among the US population (NHANES 1999-2004). Arch Intern Med. 2008;168(15):1617-24.

3. Hosseinpanah F, Barzin M, Amiri P, Azizi F. The trends of metabolic syndrome in normal-weight Tehranian adults. Ann Nutr Metab. 2011;58(2):126-32.

4. Whitlock G, Lewington S, Sherliker P, Clarke R, Emberson J, Halsey J, et al. Body-mass index and cause-specific mortality in 900000 adults: collaborative analyses of 57 prospective studies. Lancet.. 2009;373(9669):1083-96.

5. Wormser D, Kaptoge S, Di Angelantonio E, Wood AM, Pennells L, Thompson A, et al. Separate and combined associations of body-mass index and abdominal adiposity with cardiovascular disease: collaborative analysis of 58 prospective studies. Lancet. 2011;377(9771):1085-95.

6. Meigs JB, Wilson PW, Fox CS, Vasan RS, Nathan DM, Sullivan LM, et al. Body mass index, metabolic syndrome, and risk of type 2 diabetes or cardiovascular disease. J Clin Endocrinol Metab. 2006;91(8):2906-12.

7. Kip KE, Marroquin OC, Kelley DE, Johnson BD, Kelsey SF, Shaw LJ Clinical importance of obesity versus the metabolic syndrome in cardiovascular risk in women: a report from the Women's Ischemia Syndrome Evaluation (WISE) study Circulation. 2004;109(6):706-13.

8. Romero-Corral A, Somers VK, Sierra-Johnson J, Korenfeld Y, Boarin S, Korinek J, et al. Normal weight obesity: a risk factor for cardiometabolic dysregulation and cardiovascular mortality. Eur Heart J. 2009;31(6):737-46.

9. Hosseinpanah F, Barzin M, heikholeslami F, Azizi F. Effect of dif ferent obesity phenotypes on cardiovascular events in Tehran Lipid and Glucose Study (TLGS). Am J Cardiol. 2011;107(3):412-6.

10. Hamer M, Stamatakis E. Metabolically healthy obesity and risk of all-cause and cardiovascular disease mortality. J Clin Endocrino Metab. 2012;97(7):2482-8.

11. KukJL, Ardern CI. Are metabolically normal but obese individuals at lower risk for all-cause mortality? Diabetes Care. 2009;32(12):2297-9.

12. Arnlov J, Ingelsson E, Sundstrom J, Lind L. Impact of body mass index and the metabolic syndrome on the risk of cardiovascular disease and death in middle-aged men. Circulation. 2012;121(2):230-6.

13. Pataky Z, Bobbioni-Harsch E, Golay A. Open questions about metabolically normal obesity. Int J Obes (Lond). 2010;34:S18-23.

14. Bluher M. The distinction of metabolically 'healthy' from 'unhealthy' obese individuals. Curr Opin Lipidol. 2010;21(1):38-43.

15. Ferket BS, Colkesen EB, Visser JJ, Spronk S, Kraaijenhagen RA Steyerberg EW, et al. Systematic review of guidelines on cardiovascular risk assessment: Which recommendations should clinicians follow for a cardiovascular health check? Arch Intern Med 2010;170(1):27-40.

16. Clinical Guidelines on the Identification, Evaluation, and Treatment of Overweight and Obesity in Adults,The Evidence Report. National Institutes of Health.Clinical Guidelines on the Identification, Evaluation, and Treatment of Overweight and Obesity in Adults,The Evidence Report. National Institutes of Health. Obes Res. 1998;6:51S-209S.

17. Obesity: preventing and managing the global epidemic. Report of a WHO consultation.Obesity: preventing and managing the global epidemic. Report of a WHO consultation. World Health Organ Tech Rep Ser. 2000;894:1-253.

18. Cooney MT, Dudina AL, Graham IM. Value and limitations of existing scores for the assessment of cardiovascular risk: a review for clinicians. J Am Coll Cardiol. 2009;54(14):1209-27. 